https://helda.helsinki.fi

Skeletal marine animal biodiversity is built by families with long macroevolutionary lag times

\title{
Kroger, Bjorn
}

2020-10

Kroger , B \& Penny , A 2020 , ' Skeletal marine animal biodiversity is built by families with long macroevolutionary lag times ' , Nature Ecology \& Evolution , vol. 4 , no. 10 , pp. 1410-+ . https://doi.org/10.1038/s41559-020-1265-8

http://hdl.handle.net/10138/326731

https://doi.org/10.1038/s41559-020-1265-8

acceptedVersion

Downloaded from Helda, University of Helsinki institutional repository.

This is an electronic reprint of the original article.

This reprint may differ from the original in pagination and typographic detail.

Please cite the original version. 


\begin{tabular}{|c|c|c|c|}
\hline Figure \# & $\begin{array}{l}\text { Figure title } \\
\text { One sentence only }\end{array}$ & $\begin{array}{l}\text { Filename } \\
\text { This should be the name the file is } \\
\text { saved as when it is uploaded to our } \\
\text { system. Please include the file } \\
\text { extension. i.e.: Smith_ED Fig1.jpg }\end{array}$ & $\begin{array}{l}\text { Figure Legend } \\
\text { If you are citing a reference } \\
\text { for the first time in these } \\
\text { legends, please include all } \\
\text { new references in the Online } \\
\text { Methods References section, } \\
\text { and carry on the numbering } \\
\text { from the main References } \\
\text { section of the paper. }\end{array}$ \\
\hline $\begin{array}{l}\text { Extended } \\
\text { Data Fig. } \\
1\end{array}$ & $\begin{array}{l}\text { Comparison of } \\
\text { diversities of the two } \\
\text { cohorts with medium } \\
\text { lag time cohort, and } \\
\text { random sample. }\end{array}$ & Kroger_Penny_Fig_DE1.eps & 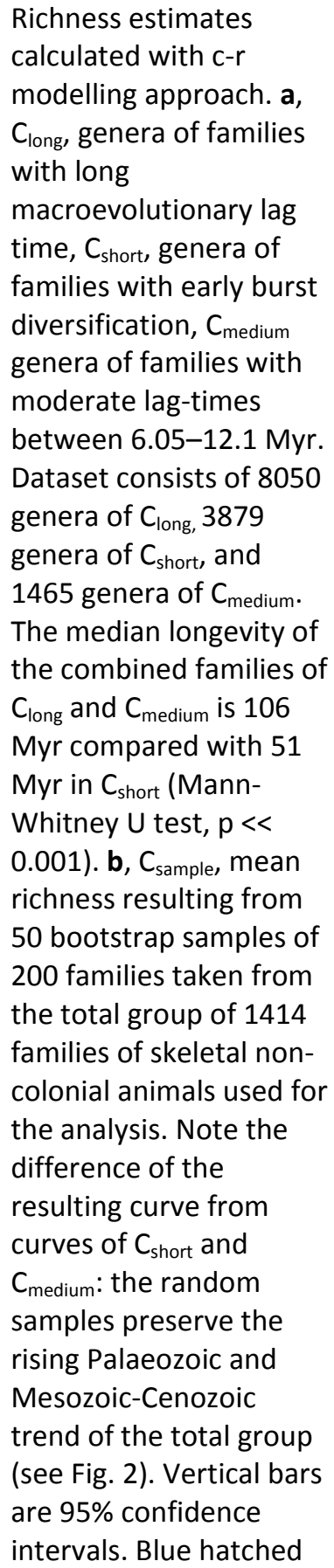 \\
\hline
\end{tabular}




\begin{tabular}{|c|c|c|c|}
\hline & & & $\begin{array}{l}\text { lines mark from left to } \\
\text { right end-Ordovician, } \\
\text { end-Devonian, end- } \\
\text { Permian, end-Triassic, } \\
\text { and end-Cretaceous } \\
\text { mass extinctions. Based } \\
\text { on a download from the } \\
\text { PaleoBioDB from } \\
\text { 16.04.2020. }\end{array}$ \\
\hline $\begin{array}{l}\text { Extended } \\
\text { Data Fig. } \\
2\end{array}$ & $\begin{array}{l}\text { Waxing and waning } \\
\text { of genus richness of } \\
\text { families. }\end{array}$ & Kroger_Penny_Fig_DE2.eps & $\begin{array}{l}\text { All family longevities are } \\
\text { standardized ranging } \\
\text { from 0-100\%. Based on } \\
\text { c-r richness estimates of } \\
\mathrm{n}=1414 \text { non-colonial } \\
\text { skeletal marine } \\
\text { metazoan families. The } \\
\text { pattern predicts that } \\
\text { maximum diversification } \\
\text { of families occurs within } \\
\text { the first two-fifths of the } \\
\text { duration of a family } \\
\text { regardless of the } \\
\text { absolute length of the } \\
\text { duration, and it also } \\
\text { predicts that in families } \\
\text { with longer durations } \\
\text { the time from first } \\
\text { appearance to peak } \\
\text { diversification is longer } \\
\text { than in families with } \\
\text { shorter durations. The } \\
\text { hat-shaped pattern is a } \\
\text { common feature of } \\
\text { clade evolution } 12 \text {. }\end{array}$ \\
\hline $\begin{array}{l}\text { Extended } \\
\text { Data Fig. } \\
3\end{array}$ & $\begin{array}{l}\text { Comparison of } \\
\text { ecological modes of } \\
\text { life of the two } \\
\text { cohorts. }\end{array}$ & Kroger_Penny_Fig_DE3.eps & $\begin{array}{l}\text { Diagrams depict relative } \\
\text { frequencies of ecological } \\
\text { life modes of genera } \\
\text { within the two cohorts. } \\
\text { Based on } \\
\text { categorisations of } 1653 \\
\text { genera of } C_{\text {short }} \text { and } 3247 \\
\text { genera of } C_{\text {long. }} \\
\text { Categories of ecological } \\
\text { modes of life from }{ }^{29} \text {, } \\
\text { and categorisations of } \\
\text { genus life modes from } \\
30 . C_{\text {long, cohort with long }} \\
\text { macroevolutionary lag; }\end{array}$ \\
\hline
\end{tabular}




\begin{tabular}{|c|c|c|c|}
\hline & & & $\begin{array}{l}\mathrm{C}_{\text {short}} \text {, cohort with short } \\
\text { macroevolutionary lag. }\end{array}$ \\
\hline $\begin{array}{l}\text { Extended } \\
\text { Data Fig. } \\
4\end{array}$ & $\begin{array}{l}\text { Results of the } \\
\text { autocorrelation } \\
\text { function (ACF) for the } \\
\text { richness curves of } \\
C_{\text {long, (cohort with }} \\
\text { long } \\
\text { macroevolutionary } \\
\text { lag) and } C_{\text {short }} \text { (cohort } \\
\text { with short } \\
\text { macroevolutionary } \\
\text { lag). }\end{array}$ & Kroger_Penny_Fig_DE4.eps & $\begin{array}{l}\text { Autocorrelations not } \\
\text { significantly different } \\
\text { from zero are similar to } \\
\text { autocorrelation } \\
\text { functions of random } \\
\text { walks }{ }^{56} \text {. Random walk } \\
\text { dynamics have been } \\
\text { previously identified and } \\
\text { analysed for } \\
\text { Phanerozoic time series } \\
\text { of diversity and } \\
\text { evolutionary rates }{ }^{56} \text {. } \\
\text { Dotted line: } 95 \% \\
\text { confidence interval. }\end{array}$ \\
\hline $\begin{array}{l}\text { Extended } \\
\text { Data Fig. } \\
5\end{array}$ & $\begin{array}{l}\text { Richness curves of a } \\
\text { reduced set of } \\
\text { skeletal marine } \\
\text { metazoans at genus } \\
\text { level. }\end{array}$ & Kroger_Penny_Fig_DE5.eps & $\begin{array}{l}\text { Families with maximum } \\
\text { diversification during } \\
\text { one of the stages with } \\
\text { duration twice of } \\
\text { maximum short-lag } \\
\text { duration (= } 12.1 \text { Myr, } \\
\text { Emsian, Famennian, } \\
\text { Tournaisian, Visean, } \\
\text { Norian, Aptian, Albian, } \\
\text { Campanian, marked in } \\
\text { red) were filtered out. } \\
\text { Clong, genera of families } \\
\text { with long } \\
\text { macroevolutionary lag } \\
\text { time (dotted line) and } \\
C_{\text {short, genera of families }} \\
\text { with early burst } \\
\text { diversification (solid } \\
\text { line). Dataset consists of } \\
\text { 1398 families, } 16 \\
\text { families less than in the } \\
\text { complete analysis. The } \\
\text { filtering has a minor } \\
\text { effect on the curves but } \\
\text { does not change the } \\
\text { strongly diverging trend } \\
\text { between C short and Clong, } \\
\text { (comp. Figure } 2 \text { ). } \\
\text { Vertical bars are } 95 \% \\
\text { confidence intervals. }\end{array}$ \\
\hline
\end{tabular}




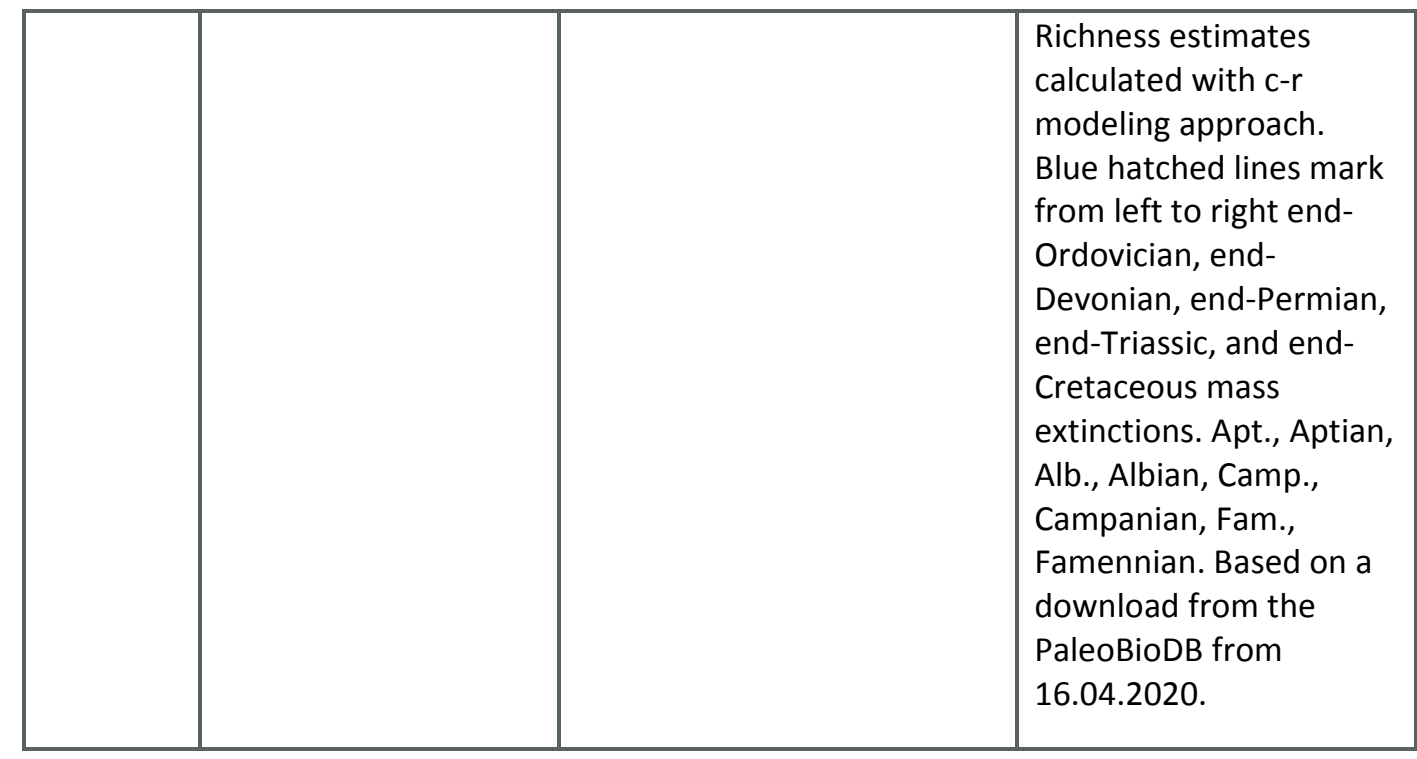

1

\begin{tabular}{|l|l|l|l|}
\hline Item & Present? & Filename & $\begin{array}{l}\text { A brief, numerical } \\
\text { description of file } \\
\text { This should be the name the file is saved as } \\
\text { when it is uploaded to our system, and } \\
\text { should include the file extension. The } \\
\text { extension must be .pdf } \\
\text { contents. }\end{array}$ \\
$\begin{array}{l}\text { Supplementary } \\
\text { Information }\end{array}$ & Yes & Kroger_Penny_SI.pdf & $\begin{array}{l}\text { i.e. Supplementary Figures } \\
\text { Discussion, and } \\
\text { Supplementary Tables 1-4. }\end{array}$ \\
\hline $\begin{array}{l}\text { Reporting } \\
\text { Summary }\end{array}$ & Yes & nr-reporting-summaryBK.pdf & $\begin{array}{l}\text { Supplementary Tables } \\
1-6\end{array}$ \\
\hline
\end{tabular}

2

3

\section{Skeletal marine animal biodiversity is built by families with long}

\section{5 macroevolutionary lag-times}

6

$7 \quad$ Björn Kröger ${ }^{1 *}$, Amelia Penny ${ }^{1}$

8

$9 \quad{ }^{1}$ Finnish Museum of Natural History, P.O.Box 44 (Jyrängöntie 2), 00014 University of Helsinki, Finland 
* bjorn.kroger@helsinki.fi

Orcid iD’s: Björn Kröger, https://orcid.org/0000-0002-2427-2364; Amelia Penny, https://orcid.org/0000-0002-4392-8090

\section{Introductory Paragraph}

The clade dynamics of marine animals have changed markedly over the Phanerozoic. Long-term diversification is associated with decreasing origination and extinction rates, and with increasing taxon longevity. Here, we use the diversification trajectories of skeletal non-colonial marine families to infer the mechanisms which generated these trends. Suggested mechanisms behind these trends include stochastic extinction of taxa with high evolutionary volatility, and selection for traits that buffer against extinction. We find an increasing predominance of Phanerozoic families with long lag times between first appearance and peak diversity, over those with 'early burst' diversification trajectories. Long-lag families persisted for longer, had lower evolutionary volatilities, higher genus-level occupancies, and genera with larger niche breadths than early-burst families. However, they do not preferentially show ecological modes known to protect against extinction. We interpret the rise of the long lag families to reflect an intensification of ecosystem-level mechanisms supporting both long-term coexistence and transient dynamics, which increased the capacity of marine ecosystems to accommodate highly diverse communities.

\section{Introduction}


Global rates of origination and extinction in marine taxa have declined markedly over the Phanerozoic Eon ${ }^{12}$. This trend in turnover rates is real and not a result of sampling bias ${ }^{2,3}$. It may result from stochastic sorting of clades for stability, whereby over geological time scales high-turnover (volatile) clades tended to become extinct more rapidly than stable clades with low turnover ${ }^{45}$. According to this model, modern marine diversity results from the successive accumulation of genera in longlived, low-volatility clades ${ }^{6}$. Moreover, the relationship between genus richness and turnover rates in marine Linnean classes has changed over geological time; high genus richness was associated with high turnover rates until the late Mesozoic, and with low turnover rates afterwards ${ }^{6}$.

Previous research has also identified physiological and ecological traits that are protective against extinction and led to increased resilience against environmental stressors, such as a fully motile habit, predatory feeding, and pelagic habitat ${ }^{6}$. Hence, resistance to extinction, tied to clade-specific traits and low volatility, has been identified as a major factor in taxonomic diversification in the marine realm. Here, we focus on taxon longevity (at family and genus level) and family specific diversity trajectories as key to understanding the Phanerozoic marine diversification. The longevities and diversity trajectories of families are a result of their species durations. All families originated with species with specific sets of physiological and ecological traits within specific ecological communities, and subsequently persisted and became accommodated within other communities in space and time. The evolutionary process whereby organisms integrate into novel environments and persist in novel association with other taxa as a result of the traits that they carry is known as ecological fitting ${ }^{7,8}$. Here we use this concept in a macroevolutionary 
context, where genera and families persist and consecutively colonize novel ecosystems in geological time.

Family longevities and their diversity trajectories are determined by family-specific properties (both traits and volatility) that allow, what we would call "macroevolutionary ecological fitting", and buffer against extinction. Similarly, though not independently, the higher-level properties of the ecosystems (e.g., spatial extent, spatial and temporal heterogeneity, niche structure, and invasibility ${ }^{9}{ }^{10}$ ), which the families are part of during geological time scales, are potential determinants of family longevity and diversity. The success of families relies on both a) the potential of their lower taxa to initially invade an ecosystem and resist extinction, and b) the capacity of ecosystems to allow invasion and to accommodate their members. Herein, we assess these two aspects of family success, and use them to infer mechanisms which might have generated the changing Phanerozoic relationship between genus richness and turnover rates.

Our analysis is based on a generalized and simplified model for diversity curves of families (and higher taxa in general). Based on the timing of the peak diversification in the curves, the model allows an evaluation of the relative importance of the family properties at time of origination versus changing ecosystem properties later in the life histories of the respective families.

\section{Results and Discussion}

\section{A generalized model for within-lineage diversity curves. Species and higher taxa} originate and disappear in a waxing and waning pattern of abundance, occupancy, and diversity ${ }^{11-13}$ (Figure 1b). The canonical view on this scenario is that new clades arrive by chance, increase in abundance, diversity, and occupancy because their novel 
traits confer a selective advantage, and eventually go extinct because that selective advantage is lost ${ }^{14}$. The interval between each taxon's expansion and decline can differ in timing and duration, but on average follows a symmetrical pattern with a climax at approximately mid-range ${ }^{12}$. A taxon's longevity and the duration of its waxing and waning are therefore generally correlated ${ }^{14}$. An early burst pattern often (but not exclusively ${ }^{15}$ ) reflects adaptive radiation, where new adaptations and ecological roles are triggered by ecological opportunity, either through a key innovation, extinction of an antagonist, or by entry into a new environment ${ }^{16-18}$. In the case of an early burst, the fate of a clade is tightly connected to an initial relaxation of selection ${ }^{17}$. In early bust scenarios, novel organismic features (i.e. morphological of functional characters) simultaneously rise toward ecological significance and often allow for the rise of a new higher taxon ${ }^{18}$. However, species and higher taxa may instead originate and persist for a long evolutionary interval with low abundance, occupancy and diversity. A change within the ecosystem, temporally and causally decoupled from the appearance and initial persistence of these taxa, triggers their rise to high abundance and diversity (e.g. via exaptations ${ }^{19}$ ) eventually resulting in what has been termed a long phylogenetic fuse ${ }^{20}$, or macroevolutionary lag-time ${ }^{21,22}$. These taxa gained ecological opportunities on geological time scales, triggered by adaptive zone changes ${ }^{23,24}$. Thus, in this model, short macroevolutionary lag time is associated with organismic novelty causing an initial rise of these families in occupancy and diversity, and long macroevolutionary lag times with ecosystems' changing capacities to accommodate members of older, pre-existing families. 
The model is based on the assumption that fossil families and genera of skeletal marine animals adequately represent evolutionary clades with their respective aggregate properties, such as evolutionary rates, occupancies, and niche breadth.

Paraphyly and variation among classifications has been identified as a source of error for diversity estimations $\left({ }^{25}\right.$, see also ${ }^{26}$ for a recent review). Statistical comparisons, however, indicate that the effects of taxonomic errors and practices of taxonomic standardization ${ }^{27}$, and the impact of "wastebasket" ${ }^{28}$ taxa for estimations of diversity are minor.

Two cohorts of families. We used data from the Paleobiology Database (PaleoBioDB, downloaded 16.04.2020) to calculate the genus level diversity curves for 1414 well documented, non-colonial skeletal marine metazoan families (comprising 15437 genera) spanning the whole Phanerozoic at chronostratigraphic stage resolution. This is c. $63 \%$ the number of extant marine animal families in the Global Biodiversity Information Facility (accessed via https:/www.gbif.org/ at 30.04.2020) and represents c. 55\% of all marine metazoan families in the PaleoBioDB. For each family, we calculated the time span from first appearance to estimated peak diversification in genus richness and termed it diversification lag-time (hereafter referred to as "lag-time"). The median lag-time for peak diversification of families is $6.05 \mathrm{Myr}$, which represents only c. $6 \%$ of the average family longevity (c. $109 \mathrm{Myr}$ ). This is slightly more than the mean length of our stage time bins (c. 5.7 Myr) and we cannot rule out that this reflects the limits of our time resolution scheme. Regardless, the relative brevity of the median lag-time qualifies it conveniently as the upper limit for our short lag-time cohort $\left(\mathrm{C}_{\text {short }}\right)$. Families with a lag-time of at least twice the median lag time (12.1 Myr) are assigned to the long lag- 
132 time cohort $\left(\mathrm{C}_{\text {long }}\right)$. Although, our distinction is arbitrary with regard to the specific 133 lag-time durations, we chose these boundaries to focus our analysis on the two 134 extremes of the complete spectrum of existing lag-times. We disregarded families 135 with moderate lag-times between 6.05-12.1 Myr. This cohort comprises c. $12 \%$ of 136 the families and $11 \%$ of the genera (173 families, 1465 genera) of the total sample.

137 Results from capture-recapture (c-r) modelling approach indicate that families of this 138 cohort are only minor contributors to the total diversity and their exclusion has no 139 effect on the significance of the results (Extended Data Fig. 1). In contrast, the $\mathrm{C}_{\text {short }}$ 140 sample comprises 710 families and 3879 genera and the $\mathrm{C}_{\text {long }}$ sample has 530 families 141 with 8050 genera.

142 As expected, the two cohorts differ significantly in longevity (median $\mathrm{C}_{\text {long }}=132$ 143 Myr, median $\mathrm{C}_{\text {short }}=51 \mathrm{Myr}$, Mann-Whitney U test, $\left.\mathrm{p}<<0.001\right)$. This difference is 144 real and not just an effect of the arbitrary filter that we set at $12.1 \mathrm{Myr}$ for the 145 minimum lag diversification time of $\mathrm{C}_{\text {long }}$, because the skew toward shorter 146 longevities in $\mathrm{C}_{\text {short }}$ persists even when families with durations less than 12.1 Myr are 147 removed (Figure 1a), and when strictly families with lag time $<6.05 \mathrm{Myr}\left(\mathrm{C}_{\text {short }}\right)$ and 148 families with lag time $>6.05 \mathrm{Myr}\left(\mathrm{C}_{\text {long }}+\right.$ families with median lag time $)$ are compared (Extended Data Fig. 1). The difference is in agreement with expectations from the model of symmetrical waxing and waning pattern of family diversity, which is also observed in our data, following the analytical protocol of Foote ${ }^{12}$ (Extended

152 Data Fig. 2). Hence, $\mathrm{C}_{\text {long }}$ predominantly represents long-lived families, and $\mathrm{C}_{\text {short }}$ 153 families with short longevities.

154 The two cohorts differ in taxonomic composition, with differences largest in 155 molluscs (44\% molluscan genera in $\mathrm{C}_{\text {short }}$ vs. $56 \%$ in $\mathrm{C}_{\text {long }}$ ) and chordates ( $8 \%$ 156 chordate genera in $\mathrm{C}_{\text {long }}$ vs. $18 \%$ in $\mathrm{C}_{\text {short }}$ ), reflecting a bias towards bivalves and 
157 gastropods within $\mathrm{C}_{\text {long }}$ and towards actinopterygian fish and mammals within $\mathrm{C}_{\text {short }}$

158 (Supplementary Table 1,2). This difference is also reflected in differences in the

159 relative abundances of "ecological modes of life" ${ }^{29}$ within the two cohorts. We

160 categorized the genera of the two cohorts using published genus level categorizations

$161{ }^{30}$. Freely moving, pelagic and predatory genera, including cephalopods, are

162 overrepresented within $\mathrm{C}_{\text {short }}$ and non-motile, surficial, suspension feeders

163 overrepresented within $\mathrm{C}_{\text {long }}$ (Extended Data Fig. 3) (Fisher's Exact Tests for

164 motility, feeding, and tiering are all with $\mathrm{p}<0.001)$. Hence, the two cohorts are not a

165 random taxonomic sample of modes of life of all skeletal marine animals in the

166 PaleoBioDB. Nor do they represent subsamples dictated by taxon membership within

167 one of the predominant classes or phyla of time specific faunas, such as the three

168 evolutionary faunas of the Phanerozoic ${ }^{31,32}$, because e.g. gastropods, bivalves,

169 mammals and actinopterygians all belong to the modern evolutionary fauna but are

170 distributed across the two cohorts.

172 Divergent cohort diversity trajectories. The Phanerozoic richness curves for $\mathrm{C}_{\text {short }}$,

$173 \mathrm{C}_{\text {long }}$ and for all taxa were estimated with the capture-recapture (c-r) approach at

174 genus level (Figure 2) ${ }^{33}$. The resulting curves for the two cohorts are distinct: The

175 richness of $\mathrm{C}_{\text {long }}$ can be best described as a succession of distinct growth curves, each

176 with a major period of diversification (Figure 2). The end-Permian and the end-

177 Cretaceous mass extinctions stand out as singular events with drastic richness

178 incursions. The richness of $\mathrm{C}_{\text {short }}$ differs from a random subsample of the total group

179 of families and from $\mathrm{C}_{\text {long }}$ in being less volatile and in having the dynamics of a

180 random walk with drift with less than $10 \%$ increase from the late Cambrian onward 
181

182

183

184

185

186

187

(Figure 2, Extended Data Fig. 1b, see also Extended Data Fig. 4, and Supplementary Table 3 for an analysis of randomness of the time series).

This pattern is consistent with expectations from models of stochastic sorting for stability ${ }^{4}$, i.e. declining volatility. Sorting for long-lived families and genera occurs via preferential extinction of highly volatile short-lived families, while families with low volatility have relatively higher extinction resistance and so persist for longer, accumulating richness. ${ }^{6}$ Supporting evidence for declining volatility at family level comes from our analysis of evolutionary rates. We used the c-r method to calculate mean genus level per-million-year rates of origination $\left(\mathrm{r}_{\mathrm{p}}\right)$, extinction $\left(\mathrm{r}_{\mathrm{q}}\right)$, and turnover $\left(r_{p}+r_{q}\right)$ for each family. As expected, the evolutionary volatility (i.e. genus level turnover) is higher in families of $\mathrm{C}_{\text {short }}$ (mean turnover $=0.79, \mathrm{n}=498$ ) than in families of $\mathrm{C}_{\text {long }}$ (mean turnover $\left.=0.40, \mathrm{n}=439\right)$ (Mann-Whitney $\mathrm{U}$ test, $\mathrm{p}<<0.001$, Supplementary Table 4).

Determinants of cohort diversity trajectories. Genera which are fully motile, predatory and/or pelagic, and which are physiologically buffered against environmental stressors have a lower extinction risk ${ }^{6}$ and therefore should be expected to be relatively more abundant within $\mathrm{C}_{\text {long. }}$. However, in our study, these ecological modes and their underlying family- and genus-specific extinction protective traits are not associated with membership in $\mathrm{C}_{\text {long }}$ (Extended Data Fig. 3). Instead, fully motile, predatory and/or pelagic genera are relatively more abundant within the $\mathrm{C}_{\text {short }}$ cohort (see above).

The families of the two cohorts differ in occupancy (i.e. for each family, the number of PaleoBioDB collections with genus occurrences from that family relative to the total number of collections with skeletal, non-colonial animal genera in the family's 
time range). Occupancy is a clade property known to be a significant determinant of extinction risk ${ }^{34}$. The occupancy of the families of $\mathrm{C}_{\text {long }}($ mean $=0.018)$ is larger than that of the families of $\mathrm{C}_{\text {short }}($ mean $=0.013)($ Mann-Whitney $\mathrm{U}$ test, $\mathrm{p}<<0.001)$, which is consistent with the lower extinction rates of the former (Supplementary Table 4, 5). Moreover, the occupancy of families of $\mathrm{C}_{\text {long }}$ is significantly larger in the time range after the macroevolutionary lag (mean occupancy before maximum diversification $=$ 0.013 vs. after maximum diversification $=0.025$, Mann-Whitney $U$ test, $p<<0.001$ ) Additionally, we estimated, based on co-occurrences in geological formations, the mean per family generalist-specialist metric $\theta$, or niche breadth ${ }^{35}$ of the genera of the two cohorts. We assumed $\theta$ to be a proxy for the ability of a family to occur in different ecological communities, following previous studies in which fossils within geological formations are interpreted as constituents of past metacommunities ${ }^{36}$. The two cohorts differ significantly with respect to their relative niche breadth; genera in $\mathrm{C}_{\text {long }}$ families generally have larger $\theta$ and thus can be interpreted as being relatively more generalist compared with $\mathrm{C}_{\text {short }}$ (Mann-Whitney $\mathrm{U}$ test, $\mathrm{p}<<0.001$, Supplementary Table 5).

Broad scale change of macroevolutionary lag time. These differences among the two cohorts can be interpreted in two ways, which are not mutually exclusive. First, they could result from different organismic properties of the genera of the two cohorts, such as dispersal capability and tolerance against stressors. Our analysis provides no positive evidence for this interpretation. Second, varying properties of marine ecosystems, such as spatial pattern ${ }^{37}$, gross production ${ }^{38}$ or nutrient exchange ${ }^{39}$ are factors that potentially determine longevities, occupancy, and relative niche 
230 breadth $\left(\right.$ e.g. $\left.{ }^{40},{ }^{41}\right)$. Ecosystem changes can occur independently from genus and

231 family originations and could allow or impede diversification of a wide range of

232 skeletal marine animals long after their origination and hence change the relative

233 diversities of $\mathrm{C}_{\text {short }}$ and $\mathrm{C}_{\text {long }}$ within ecological communities. Throughout the

234 Phanerozoic the macroevolutionary lag time of skeletal marine animal families

235 increased dramatically across a wide range of marine ecological communities. The

236 relative number of genera of $\mathrm{C}_{\text {long }}$ occurring within geological formations (interpreted

237 as reflecting a record of past ecological communities ${ }^{36}$ ) tripled during the Palaeozoic

238 and almost doubled during the Mesozoic-Cenozoic eras (Figure 3A). And the relative

239 abundance of formations that contain more than $75 \%$ genera belonging to $\mathrm{C}_{\text {long }}$ more

240 than tripled since the beginning of the Mesozoic (Figure 3B). This relative increase in

$241 \mathrm{C}_{\text {long }}$ could just be an aggregated effect of the mechanism of stochastic sorting, where

242 clades with high evolutionary volatilities, narrow niches and low occupancies

243 increasingly became filtered out, and ecosystems became increasingly dominated by

244 long lived clades. However, the main intervals of richness increase of $\mathrm{C}_{\text {long, }}$, the early

245 Palaeozoic and late Mesozoic-Cenozoic eras, coincide with intervals of major

246 diversification and restructuring of marine ecosystems ${ }^{42}{ }^{43}$.These temporal

247 correspondences suggest that structural changes in marine ecosystems during these

248 diversifications broadly increased the ecosystems' capacities to allow families to

249 persist for longer and to give opportunities to families to diversify long after their

250 first appearances. It is a subject for future research to identify specific ecosystem-

251 level mechanisms which promoted ecological opportunity and high diversity during

252 these transitions.

253 
254

255

256

257

258

259

260

261

262

263

264

265

266

267

268

269

270

271

272

273

274

275

276

277

278

Mechanisms for diversification with increasing lag times. The increasing

dominance of marine skeletal animal biodiversity by families with predominantly generalist genera, with long durations and macroevolutionary lags is consistent with a declining role for ecological specialisation within families in determining evolutionary fitness. Several complementary mechanisms could explain this trend, and we examine them below.

One potential mechanism that could allow families to accumulate species and genus diversity under regimes of increasing lag time, niche breadth and occupancies is ecosystem dynamics in steady rapid transition, i.e. in ecosystems with transient dynamics, facilitated by dispersal among connected local communities.

Metacommunity diversification models with transient dynamics predict increased species longevities and delayed peak diversifications ${ }^{44}{ }^{45}$. Conversely, in these models, shorter longevities, early burst diversification and decelerating richness accumulation are associated with ecological differentiation of species. Although our results reflect higher taxonomic levels, they are consistent with these predictions insofar as short macroevolutionary lag times of families are here equated with diversification generated by ecological differentiation and opportunity at origination. Higher levels of ecological differentiation in $\mathrm{C}_{\text {short }}$ are also consistent with lower average genus $\theta$ (i. e. more specialist genera) and smaller family sizes (i.e. higher phylogenetic distinctiveness) in this cohort compared with $\mathrm{C}_{\text {long }}$ (median per-millionyear family size $\mathrm{C}_{\text {short }}=0.10$ genera, $\mathrm{C}_{\text {long }}=0.49$ genera, Mann-Whitney $\mathrm{U}$ test, $\mathrm{p}<<0.001)$.

In addition to an increase in transient dynamics, long-term intensification of mechanisms which promote long-term coexistence of increasing numbers of species within ecosystems are also consistent with our results. Equalizing processes, which 
reduce fitness differences between members of a community, and stabilizing processes, which increase the intensity of negative intraspecific interactions relative to interspecific interactions, can work together to promote high community diversity ${ }^{46}$. Our global analyses do not allow us to infer the nature and relative importance of these ecosystem-level mechanisms. However, we note that more intense intraspecific competition might be expected for $\mathrm{C}_{\text {short }}$ genera, which are on average more specialist than $\mathrm{C}_{\text {long }}$ genera, while reductions in fitness differences might reduce the need for ecological differentiation or organismic novelty, and favour accommodation of generalists into new ecosystems $\left(\mathrm{C}_{\text {long }}\right)$.

The increasing proportion of long-lived families and families with long macroevolutionary lag times among skeletal marine animals throughout the Phanerozoic thus can be interpreted as a result of multiple mechanisms, including a rise in transient dynamics and long-term coexistence in marine communities. This interpretation is consistent with previous analysis of diversity partitioning among benthic communities, which revealed a decreasing coupling of beta and gamma diversity throughout the Phanerozoic ${ }^{36}$.

\section{Conclusions}

Throughout the Phanerozoic, the flux of novel genera from marine skeletal animal families with early burst diversification was relatively stable, without a substantial increase in diversity from the early Palaeozoic onward. Small per family genus numbers, low occupancy and narrow relative niche breadth in the cohort of families with early burst diversification suggest that early burst diversification is associated with organismic novelty and ecological differentiation. In contrast, families with long macroevolutionary lag times, and with high longevities constitute a progressively 
larger fraction of marine diversity over the Phanerozoic. Families with long lag times have high per family genus numbers, and wide niche breadths of genera, suggesting that their diversification may have resulted from ecological processes which reduce the role of ecological specialisation in determining evolutionary fitness, and instead allow generalist families to persist over long timescales.

Macroevolutionary lag time, longevity and relative niche breadth of families are also determined by ecosystem level properties, such as temporal fluctuation, spatial heterogeneity and areal extent. Although our study does not allow us to identify specific ecosystem level properties associated with the diversification, our results reveal that marine ecosystems increased their capacity to accommodate a broad range of skeletal animal genera giving opportunity to allow increasing niche breadth among genera, and long macroevolutionary lag time within families.

\section{Methods}

The focus of our analysis was at genus and family level, because genera and families are traditionally excellently documented in the paleontological literature, such as in the Treatise of Invertebrate Paleontology and in the Paleobiology Database (PaleoBioDB). We based our analysis on fossil genus occurrences of brachiopods, echinoderms, molluscs and arthropods, agnathans, and marine gnathostomes from the Paleobiology Database (PaleoBioDB) (downloaded 16th April 2020) (Supplementary Table 1, 2). Colonial skeletal metazoans, such as anthozoans, sponges, and bryozoans were excluded from our analyses, because we assumed they contain a larger percentage of wastebasket, ambiguous and potentially non-monophyletic families. The download comprises 745880 occurrences ranging from the base of the Cambrian to the Holocene and includes extant taxa. We filtered the download for occurrences 
identified to at least genus level, and assigned the stratigraphic ages of the occurrences to time bins at the resolution of chronostratigraphic stages. We did not filter for possible "wastebasket taxa”, i.e. groups resulting from inadequate systematic attention or determination. Although these may be abundant in the dataset of long ranging taxa, previous analyses showed that their impact on diversity estimations is minimal to statistically insignificant ${ }^{28}{ }^{47}$. We excluded all occurrences with less than chronostratigraphic stage time resolution from the analysis. The absolute age boundaries were taken from the International Chronostratigraphic Chart (v2018/08) ${ }^{48}$. The median absolute time range of the chronostratigraphic stages is 4.8 Myr, and the mean 5.7 Myr. The filtering procedure left us with 459945 occurrences of a total of 20805 genera and 2988 families at chronostratigraphic stage resolution. Genus and family longevities were estimated from the filtered dataset as time range from first to last occurrences. We calculated genus level richness curves of all families with occurrences in more than two chronostratigraphic stages with the capture-recapture (c-r) modelling approach ${ }^{49}$ which results in 1414 individual family richness curves. The method was conceptually transferred from ecology to fossil data following Connolly and Miller ${ }^{50}$, and Liow and Nichols ${ }^{33}$ and allows for an explicit estimation of sampling probability, which in fossil data is a mixed effect of preservation and sampling. A presence-absence matrix was constructed based on the filtered and binned PaleoBioDB occurrences. This matrix served for the fitting of explicit models for richness estimation with time varying probabilities of survival, sampling/preservation, and origination. We fitted the Jolly-Seber model following the POPAN formulation ${ }^{51}$. 
352 Evolutionary rates were estimated by using the Pradel seniority model ${ }^{52}$. We

353 estimated survival, seniority and sampling probabilities, along with diversification

354 rates of genera, which are transformed into per-million-year extinction $\left(\mathrm{r}_{\mathrm{q}}\right)$,

355 origination $\left(r_{p}\right)$ rates. This transformation is necessary, because probabilities between

356 time-intervals of different lengths cannot be compared directly ${ }^{53}$. For a detailed

357 description of the transformations see ${ }^{53}$. Additionally, we estimated instantaneous

358 extinction and origination rates of genera with Alroy's ${ }^{54}$ statistical estimator and as

359 per-capita rates ${ }^{11}$ using the R package divDyn, version $0.70{ }^{55}$. For each family we

360 calculated the genus level $r_{q}$ and $r_{p}$ curves and calculated the means for a comparison

361 of the evolutionary volatility. The divDyn calculation is based on the 10-Myr time

362 bin scheme and thus the results are not directly comparable. However, the

363 calculations consistently resulted in lower mean extinction rates for $\mathrm{C}_{\text {long }}$

364 (Supplementary Table 4).

365 We filtered the time binned PaleoBioDB download for genus occurrences of families

366 assigned to the two cohorts ( $\mathrm{C}_{\text {long }} 257387$ occurrences; $\mathrm{C}_{\text {short }} 74272$ occurrences) and

367 estimated a richness curve for each of the two data sets individually, and for the total

368 dataset, using the c-r modeling approach. We limited the time range of our analysis in

369 order to minimize boundary effects. A potential boundary effect toward the present is

370 caused by the declining number of taxa of $\mathrm{C}_{\text {long }}$ in the younger time bins, because

371 longevities ranging from origination to extinction cannot be projected into the future.

372 Taxa originating e.g. in the Pleistocene can only have maximal longevities that range

373 through the Holocene. This shifts longevities toward lower estimates. Similar

374 problems occur with taxa that went extinct at the lowermost Cambrian. We therefore 
375 limit the analysis of our c-r results to an interval ranging from Cambrian Stage 3 -

376 the late Paleogene Chattian Stage.

377 We tested the resulting time series of the richness for random walk dynamics,

378 following ${ }^{56}$, and or stationarity, drift and trend with the Augmented Dickey-Fuller

379 test for the null hypothesis of a unit $\operatorname{root}^{57}$ (Supplementary Table 3).

380 We decided to compare longevity and lag-time on a continuous time scale and not on

381 a discrete time scale that would be based on the number of stages. Although the

382 occurrences are binned within discrete stage level units, the length of the individual

383 stages varies considerably. This introduces a bias, towards longer durations where

384 stage-level time resolution is low and towards shorter durations where time resolution

385 is high, because short ranging taxa are covered in the binning scheme in a varying

386 degree. Within a discrete time scale this bias would be obstructed. In our continuous

387 time scale the bias is present (Supplementary Table 6), but explicitly quantifiable by

388 comparing time bin length with our estimates. We find that the variation within our

389 estimates is large enough to overprint the expected dependence with time bin length

390 and we find no correlations between time bin length and lag time (Supplementary

391 Table 6).

392 As an additional test for the bias introduced by intervals with poor time resolution,

393 we filtered out all families of $\mathrm{C}_{\text {long }}$ which have their maximum diversification within

394 one of the six stage bins with durations more than twice as long as the median $\mathrm{t}_{\mathrm{r} \Delta \max }$

395 (Emsian, Famennian, Tournaisian, Visean, Norian, Aptian, Albian, Campanian). In

396 these exceptionally long stage bins detection of $\mathrm{C}_{\text {short }}$ is impossible. The resulting

397 diversity curves preserve the divergent trends of $\mathrm{C}_{\text {long }}$ and $\mathrm{C}_{\text {short }}$ (Extended Data Fig.

$3985)$. 
We used the tabulated genus level assignments of marine genera to ecological modes of life of ${ }^{30}$, defined in ${ }^{29}$ into tiering position relative to sea floor, degree of motility and feeding mode to compare the life-modes of the two different cohorts (Extended Data Fig. 3).

For our analysis of the waxing and waning pattern of family richness we followed a procedure slightly modified from Foote ${ }^{12}$. We standardized the family longevity by dividing each family range into equal time bins ranging from 1-100. We standardized the estimated c-r richness of each family to 100 and calculated the percentage of genera in each chronostratigraphic stage, rounded toward its nearest integers. We then calculated the relative duration of each family range through chronostratigraphic stages. Next, we assigned the standardized genus number to each of the respective standardized time bins. The frequency distribution of numbers of genera within the standardized longevity for all families gives our hat-shaped waxing and waning pattern (Extended Data Fig. 2).

Additionally, for each family of $\mathrm{C}_{\text {long }}$ and $\mathrm{C}_{\text {short }}$ we filtered the PaleoBioDB download for occurrences within the family time range, counted the number of collections with genus occurrences of the respective family and divided it by the total number of collections with genera in this subset. This ratio is our proxy for occupancy.

The average niche breadth of a family was calculated using the generalist-specialist metric $\theta^{35}$, applied to each genus in a family. The metric is based on an analysis of community difference (presence-absence beta diversity) across sites where a taxon occurs. Taxa which occur at a number of sites which show high levels of community difference are considered generalists, while taxa which occur at few sites and/or consistently occur alongside a similar assemblage of other taxa are considered 
423 specialists. We used the pairwise Jaccard dissimilarity to calculate beta diversity

424 among genera in formations as a turnover estimate following the suggestions of ${ }^{58}$.

425

426

427

428

429

430

431

432

433

434

435

436

437

438

439

440

441

442

443

444

445

446

\section{Data Availability}

The data downloaded from the PaleoBioDB (https://paleobiodb.org) and the URLs for retrieving data used to generate the results are available in the accompanying $\mathrm{R}$ code, which is available on https://doi.org/10.5281/zenodo.3901507

\section{Code Availability}

The $\mathrm{R}$ code for all analyses is available on https://doi.org/10.5281/zenodo.3901507

\section{Competing interests}

The authors declare no competing interests.

\section{Acknowledgments}

We are grateful for discussions and commentaries on earlier versions of the manuscript from Indrè Žliobaite, Mikael Fortelius, and Stefan Geritz (all Helsinki, Finland). This is official Paleobiology Database Publication 374.

\section{Author Contributions}

A.P. and B.K. contributed to the design and implementation of the research, to the analysis of the results and to the writing of the manuscript. 
447

448 1. van Valen, L. M. Resetting the Phanerozoic community evolution. Nature 307, 449 93-106 (1984).

450 2. Alroy, J. Dynamics of origination and extinction in the marine fossil record.

451

452

453

454

455

456

457

458

459

460

461

462

463

464

465

466

467

468

469

470

471

\section{References}

Proceedings of the National Academy of Sciences 105, 11536-11542 (2008).

3. Foote, M. Origination and extinction through the Phanerozoic: A new approach. Journal of Geology 111, 125-148 (2003).

4. Gilinsky, N. L. Volatility and the Phanerozoic decline of background extinction intensity. Paleobiology 20, 445-458 (1994).

5. Lieberman, B. S. \& Melott, A. L. Declining volatility, a general property of disparate systems: from fossils, to stocks, to the stars. Palaeontology 56, $1297-$ 1304 (2013).

6. Knope, M. L., Bush, A. M., Frishkoff, L. O., Heim, N. A. \& Payne, J. L. Ecologically diverse clades dominate the oceans via extinction resistance. Science 367, 1035 (2020).

7. Janzen, D. H. On ecological fitting. Oikos 45, 308-310 (1985).

8. Agosta, S. J. \& Klemens, J. A. Ecological fitting by phenotypically flexible genotypes: implications for species associations, community assembly and evolution. Ecology Letters 11, 1123-1134 (2008).

9. Nielsen, S. N. \& Muller, F. II. 2.2 Emergent Properties of Ecosystems. Handbook of ecosystem theories and management 195 (2000).

10. Hui, C. et al. Defining invasiveness and invasibility in ecological networks. Biological Invasions 18, 971-983 (2016).

11. Foote, M. et al. Rise and fall of species occupancy in Cenozoic fossil mollusks. Science 318, 1131-1134 (2007). 
472 12. Foote, M. Symmetric waxing and waning of marine invertebrate genera.

$473 \quad$ Paleobiology 33, 517-529 (2007).

474 13. Liow, L. H. \& Stenseth, N. C. The rise and fall of species: implications for

475 macroevolutionary and macroecological studies. Proceedings of the Royal

$476 \quad$ Society of London B: Biological Sciences 274, 2745-2752 (2007).

477 14. Zliobaite, I., Fortelius, M. \& Stenseth, N. C. Reconciling taxon senescence with

478 the Red Queen's hypothesis. Nature 552, 92-95 (2017).

479 15. Gillespie, R. G. et al. Comparing Adaptive Radiations Across Space, Time, and

480 Taxa. Journal of Heredity 111, 1-20 (2020).

481 16. Losos, J. B. Adaptive radiation, ecological opportunity, and evolutionary

482 determinism: American Society of Naturalists EO Wilson Award address. The

$483 \quad$ American Naturalist 175, 623-639. (2010).

484 17. Yoder, J B et al. Ecological opportunity and the origin of adaptive radiations.

485 Journal of Evolutionary Biology 23, 1581-1596 (2010).

486 18. Erwin, D. H. Novelty and innovation in the history of life. Current Biology 25,

$487 \quad$ R930 - R940 (2015).

488 19. Gould, S. J. \& Vrba, E. S. Exaptation, - a Missing Term in the Science of Form.

$489 \quad$ Paleobiology 8, 4-15 (1982).

490 20. Cooper, A. \& Fortey, R. Evolutionary explosions and the phylogenetic fuse.

491 Trends in Ecology \& Evolution 13, 151-156 (1998).

492 21. Jablonski, D. \& Bottjer, D. J. in Major evolutionary radiations (eds Taylor, P.

493 D. \& Larwood, G. P.) 17-57 (Systematics Association, Oxford, 1990).

494 22. Jablonski, D. Approaches to macroevolution: 1. General concepts and origin of $495 \quad$ variation. Evolutionary biology 44, 427-450 (2017). 
496

497

498

499

500

501

502

503

504

505

506

507

508

509

510

511

512

513

514

515

516

517

518

519

23. Uyeda, J. C., Hansen, T. F., Arnold, S. J. \& Pienaar, J. The million-year wait for macroevolutionary bursts. Proceedings of the National Academy of Sciences 108, 15908-15913 (2011).

24. Kröger, B., Desrochers, A. \& Ernst, A. The Reengineering of reef habitats during the Great Ordovician Biodiversification Event. Palaios 32, 584-599 (2017).

25. Robeck, H. E., Maley, C. C. \& Donoghue, M. J. Taxonomy and temporal diversity patterns. Paleobiology 26, 171-187 (2000).

26. Hendricks, J. R., Saupe, E. E., Myers, C. E., Hermsen, E. J. \& Allmon, W. D. The generification of the fossil record. Paleobiology 40, 511-528 (2014).

27. Wagner, P. J., Aberhan, M., Hendy, A. \& Kiessling, W. The effects of taxonomic standardization on sampling-standardized estimates of historical diversity. Proceedings of the Royal Society B: Biological Sciences 274, 439-444 (2007).

28. Plotnick, R. E. \& Wagner, P. J. Roundup of the usual suspects: common genera in the fossil record and the nature of the wastebasket taxa. Paleobiology 32, 126146 (2006).

29. Bambach, R. K., Bush, M A, Erwin, D H. Autecology and the filling of ecospace: key metazoan radiations. Palaeontology 50, 1-22 (2007).

30. Knope, M. L., Heim, N. A., Frishkoff, L. O. \& Payne, J. L. Limited role of functional differentiation in early diversification of animals. Nature Communications 6, 1-6 (2015).

31. Sepkoski, J. J. A kinetic model of Phanerozoic taxonomic diversity. III. PostPaleozoic families and mass extinctions. Paleobiology 10, 246-267 (1984). 
520

521

522

523

524

525

526

527

528

529

530

531

532

533

534

535

536

537

538

539

540

541

542

543

544

32. Alroy, J. The shifting balance of diversity among major marine animal groups. Science 329, 1191-1194 (2010).

33. Liow, L. H. \& Nichols, J. D. in The Paleontological Society Short Course, October 30th 2010 (eds Alroy, J. \& Hunt, G.) 81-94 2010).

34. Kiessling, W. \& Kocsis, Á., T. Adding fossil occupancy trajectories to the assessment of modern extinction risk. Biology letters 12, 20150813 (2016).

35. Fridley, J.D., Vandermast, D. B., Kuppinger, D.M., Manthey M.L. \& Peet, R. K. Co-occurrence based assessment of habitat generalists and specialists: a new approach for the measurement of niche width. Journal of Ecology 95, 707-722 (2007).

36. Hofmann, R., Tietje, M. \& Aberhan, M. Diversity partitioning in Phanerozoic benthic marine communities. Proceedings of the National Academy of Sciences USA 116, 79 (2019).

37. Bottjer, D. J., Hagadorn, J. W. \& Dornbos, S. Q. The Cambrian substrate revolution. GSA today 10, 1-7 (2000).

38. Knoll, A. H. \& Follows, M. J. A bottom-up perspective on ecosystem change in Mesozoic oceans. Proceedings of the Royal Society B: Biological Sciences 283, 20161755 (2016).

39. Bambach, R. K. Seafood through time: changes in biomass, energetics, and productivity in the marine ecosystem. Paleobiology 19, 372-397 (1993).

40. Westrop, S. R. The life habits of the Ordovician illaenine trilobite Bumastoides. Lethaia 16, 15-24 (1983).

41. O’Dea, A. \& Jackson, J. Environmental change drove macroevolution in cupuladriid bryozoans. Proceedings of the Royal Society B: Biological Sciences 276, 3629-3634 (2009). 
545

546

547

548

549

550

551

552

553

554

555

556

557

558

559

560

561

562

563

564

565

566

567

568

569

42. Rasmussen, C. M. Ø., Kröger, B., Nielsen, M. L. \& Colmenar, J. Cascading trend of Early Paleozoic marine radiations paused by Late Ordovician extinctions. Proceedings of the National Academy of Sciences USA 116, 7207 (2019).

43. Bush, A. M. \& Bambach, R. K. Sustained Mesozoic, ÄìCenozoic diversification of marine Metazoa: A consistent signal from the fossil record. Geology 43, 979$982(2015)$.

44. Leibold, M. A. \& McPeek, M. A. Coexistence of the niche and neutral perspectives in community ecology. Ecology 87, 1399-1410 (2006).

45. McPeek, M. A. The ecological dynamics of clade diversification and community assembly. The American Naturalist 172, E270-E284 (2008).

46. Chesson, P. Mechanisms of maintenance of species diversity. Annual Review of Ecology and Systematics 31, 343-366 (2000).

47. Wagner, P. J., Aberhan, M., Hendy, A. \& W., K. The effects of taxonomic standardization on occurrence-based estimates of diversity. Proceedings of the Royals Society of London B. Biological Sciences 274, 439-444 (2007).

48. Cohen, K. M., Harper, D. A. T. \& Gibbard, P. L. ICS International Chronostratigraphic Chart 2018/08. International Commission on Stratigraphy, IUGS. www.stratigraphy.org (accessed: 2018/12/12) (2018).

49. Nichols, J. D. \& Pollock, K. H. Estimating taxonomic diversity, extinction rates, and speciation rates from fossil data using capture-recapture models. Paleobiology 9, 150-163 (1983).

50. Connolly, S. R. \& Miller, A. I. Joint Estimation of Sampling and Turnover Rates from Fossil Databases: Capture-Mark-Recapture Methods Revisited. Paleobiology 27, 767-751 (2001). 
570

571

572

573

574

575

576

577

578

579

580

581

582

583

584

585

586

587

588

589

590

591

51. Schwarz, C. J. \& Arnason, A. N. A General Methodology for the Analysis of Capture-Recapture Experiments in Open Populations. Biometrics 52, 860-873 (1996).

52. Pradel, R. Utilization of Capture-Mark-Recapture for the Study of Recruitment and Population Growth Rate. Biometrics 52, 703-709 (1996).

53. Liow, L. H., Reitan, T. \& Harnik, P. G. Ecological interactions on macroevolutionary time scales: clams and brachiopods are more than ships that pass in the night. Ecology Letters 18, 1030-1039 (2015).

54. Alroy, J. A more precise speciation and extinction rate estimator. Paleobiology 41, 633-639 (2015).

55. Kocsis, Á. T., Reddin, C. J., Alroy, J. \& Kiessling, W. The r package divDyn for quantifying diversity dynamics using fossil sampling data. Methods in Ecology and Evolution 10, 735-743 (2019).

56. Cornette, J. L. \& Lieberman, B. S. Random walks in the history of life. Proceedings of the National Academy of Sciences 101, 187-191 (2004).

57. Fuller, W. A. Introduction to Statistical Time Series (John Wiley and Sons, New York,

58. Manthey, M. \& Fridley, J. D. Beta diversity metrics and the estimation of niche width via species co-occurrence data: reply to Zeleny. Journal of Ecology 18-22 (2009). 
592

593

594

595

596

597

598

599

600

601

602

603

604

605

606

607

608

609

610

611

612

613

614

615

616

Figure legends

Fig. 1: Distinction of two cohorts of families of skeletal marine metazoans.

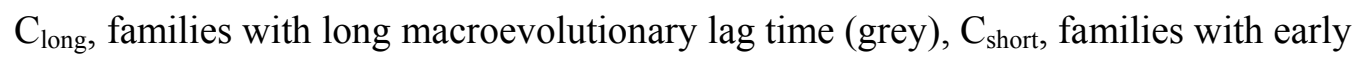
burst diversification (black). a, Frequency distribution of families with longevities $>$ 12.1 Myr. Note the skew of $\mathrm{C}_{\text {short }}$ toward shorter longevities. Mann-Whitney $\mathrm{U}$ test between the two samples with $\mathrm{p}<<0.001$. Mode of $\mathrm{C}_{\text {short }}$ at 20-40 Myr, Mode of $\mathrm{C}_{\text {long }}$ at 40-60 Myr. b, Illustrative examples of early Palaeozoic families of trilobites with early burst and long macroevolutionary lag diversification pattern. Spindle width $=$ relative genus richness. Based on a download from the PaleoBioDB from 16.04.2020. For abbreviations see Figure 2.

\section{Fig. 2: Richness curves of skeletal marine metazoans at genus level}

$\mathrm{C}_{\text {long, }}$ genera of families with long macroevolutionary lag time (dotted line) and $\mathrm{C}_{\text {short, }}$ genera of families with early burst diversification (solid line). Vertical bars are $95 \%$ confidence intervals. Compare the different trajectories of the two cohorts. Richness estimates calculated with c-r modeling approach. Blue hatched lines mark from left to right end-Ordovician, end-Devonian, end-Permian, end-Triassic, and end Cretaceous mass extinctions. Cm, Cambrian; O, Ordovician; S, Silurian; D, Devonian; C,

Carboniferous; P, Permian; T, Triassic; J, Jurassic; K, Cretaceous; Pg, Paleogene.

Based on a download from the PaleoBioDB from 16.04.2020.

Fig. 3: The increasing abundance of $C_{\text {long }}$ genera in the fossil record.

a, Mean number of genera belonging to $\mathrm{C}_{\text {long }}$ in a geological formation relative to all skeletal non-colonial marine animals in the formation. Vertical bars are $95 \%$ 
617 confidence intervals. b, Number of formations containing more than $75 \%$ genera

618 belonging to $\mathrm{C}_{\text {long }}$ relative to the total number of formations per stage. Based on

61918040 genus occurrences in 6477 formations. Based on a download from the

620 PaleoBioDB from 16.04.2020. For abbreviations see Figure 2.

621 

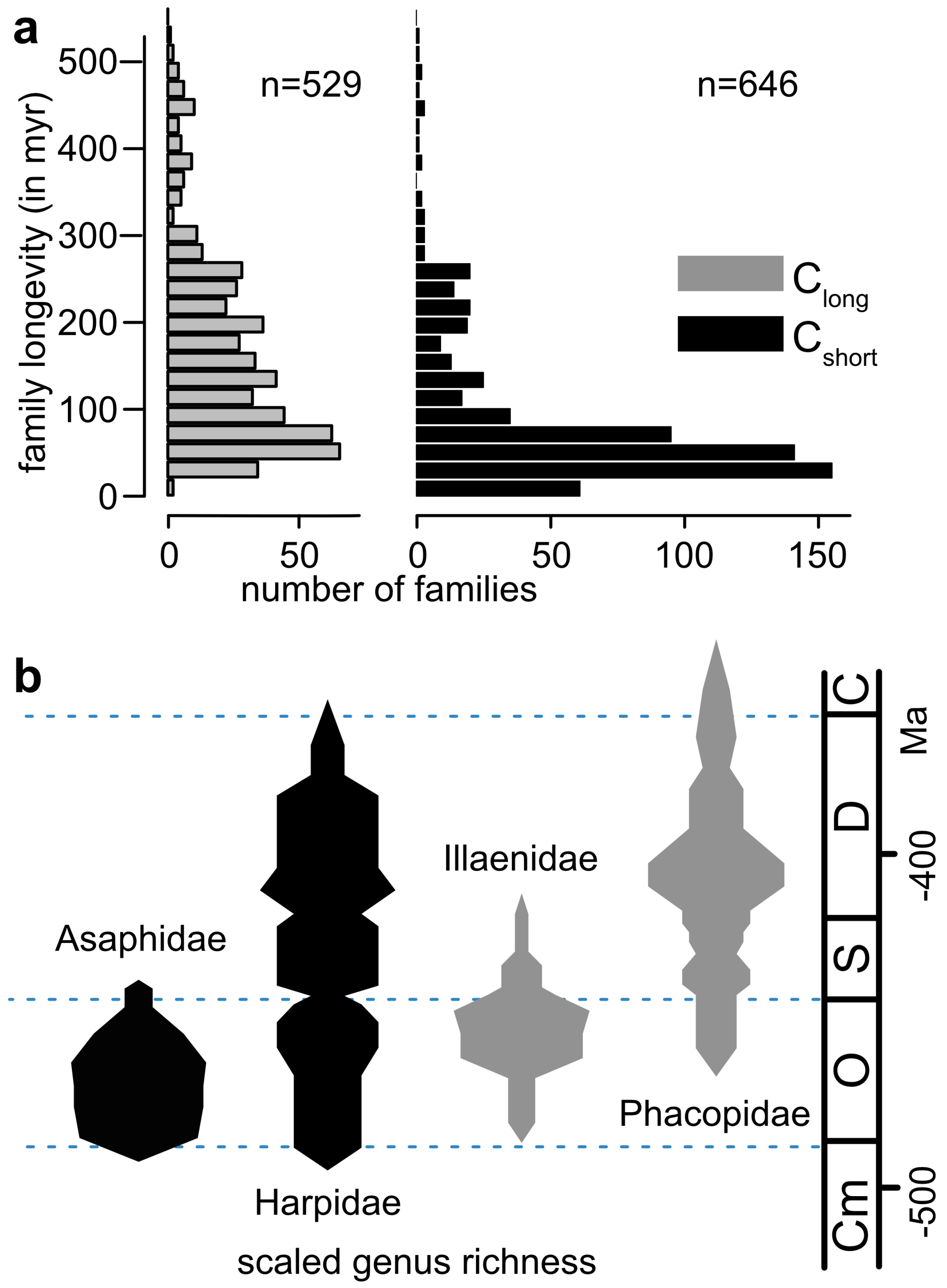

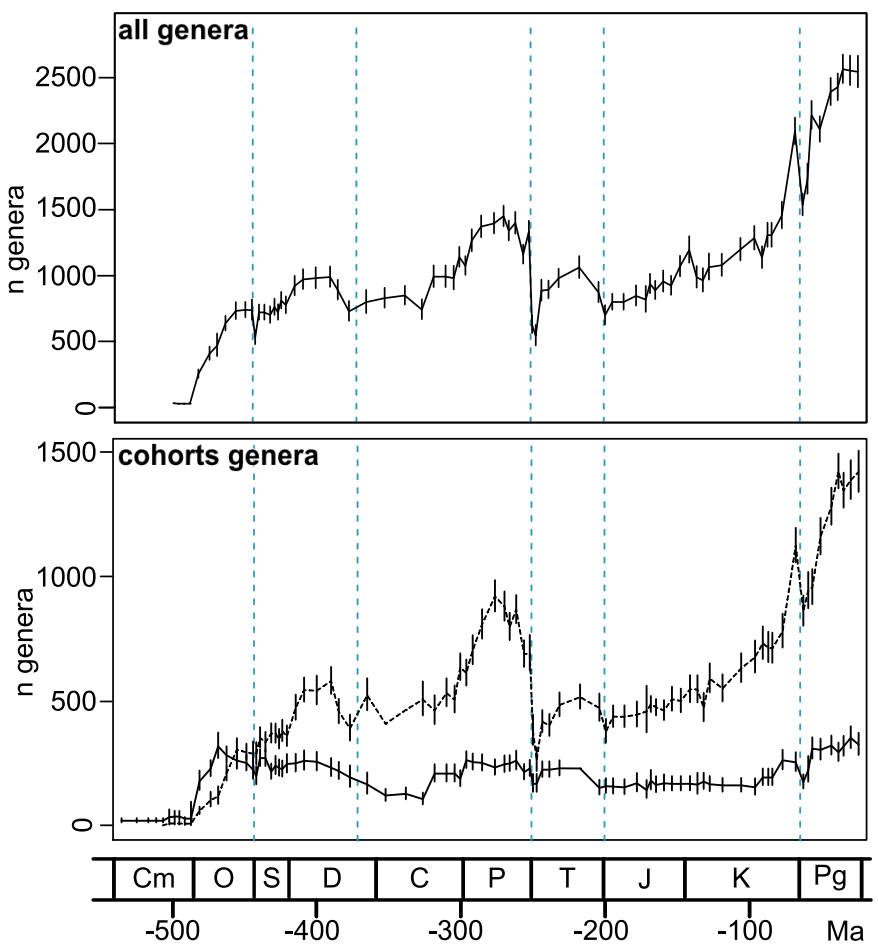
